\title{
Communications of Staphylococcus aureus and non-aureus Staphylococcus species from bovine intramammary infections and teat apex colonization
}

\author{
Yasser S. Mahmmod, ${ }^{*} \dagger^{1,2}$ Ilka Christine Klaas, ${ }^{3}$ Line Svennesen, ${ }^{*}$ Karl Pedersen, $\ddagger$ and Hanne Ingmer* \\ ${ }^{*}$ Department of Veterinary and Animal Sciences, Faculty of Health and Medical Sciences, University of Copenhagen, DK-1870 Frederiksberg C, \\ Denmark \\ †Infectious Diseases, Department of Animal Medicine, Faculty of Veterinary Medicine, Zagazig University, 44511-Zagazig, Sharkia Province, \\ Egypt \\ ‡National Veterinary Institute, Technical University of Denmark, 2800 Kongens Lyngby, Denmark
}

\begin{abstract}
The role of non-aureus staphylococci (NAS) in the risk of acquisition of intramammary infections with Staphylococcus aureus is vague and still under debate. The objectives of this study were to (1) investigate the distribution patterns of NAS species from milk and teat skin in dairy herds with automatic milking systems, and (2) examine if the isolated NAS influences the expression of $S$. aureus virulence factors controlled by the accessory gene regulator (agr) quorum sensing system. In 8 herds, 14 to 20 cows with elevated somatic cell count were randomly selected for teat skin swabbing and aseptic quarter foremilk samples from right hind and left front quarters. Teat skin swabs were collected using the modified wet-dry method and milk samples were taken aseptically for bacterial culture. Colonies from quarters with suspicion of having NAS in milk or teat skin samples (or both) were subjected to MALDITOF assay for species identification. To investigate the interaction between $S$. aureus and NAS, 81 isolates NAS were subjected to a qualitative $\beta$-galactosidase reporter plate assay. In total, 373 NAS isolates were identified representing 105 from milk and 268 from teat skin of 284 quarters $(=142$ cows). Sixteen different NAS species were identified, 15 species from teat skin and 10 species from milk. The most prevalent NAS species identified from milk were Staphylococcus epidermidis (50\%), Staphylococcus haemolyticus (15\%), and Staphylococcus chromogenes (11\%), accounting for $76 \%$. Meanwhile, the most prevalent NAS species from teat skin were Staphylococcus equorum (43\%), S. haemolyticus (16\%),
\end{abstract}

\footnotetext{
Received December 19, 2017.

Accepted April 10, 2018.

${ }^{1}$ Current address: IRTA, Centre de Recerca en Sanitat Animal (CReSA, IRTA-UAB), Campus de la Universitat Autònoma de Barcelona, 08193 Bellaterra, Barcelona, Spain.

${ }^{2}$ Corresponding author: yasser@sund.ku.dk or yasser.mahmmod@

${ }^{3}$ Current address: DeLaval International AB, Tumba, Sweden.
} irta.cat and Staphylococcus cohnii (14\%), accounting for $73 \%$. Using reporter gene fusions monitoring transcriptional activity of key virulence factors and regulators, we found that out of 81 supernatants of NAS isolates, $77 \%$ reduced expression of hla, encoding a-hemolysin, $70 \%$ reduced expression of RNAIII, the key effector molecule of $a g r$, and $61 \%$ reduced expression of spa encoding protein A of $S$. aureus, respectively. Our NAS isolates showed 3 main patterns: (1) downregulation effect such as S. chromogenes (milk) and Staphylococcus xylosus (milk and teat), (2) no effect such as Staphylococcus sciuri (teat) and S. vitulinus (teat), and the third pattern (c) variable effect such as S. epidermidis (milk and teat) and S. equorum (milk and teat). The pattern of cross-talk between NAS species and $S$. aureus virulence genes varied according to the involved NAS species, habitat type, and herd factors. The knowledge of how NAS influences $S$. aureus virulence factor expression could explain the varying protective effect of NAS on $S$. aureus intramammary infections.

Key words: non-aureus staphylococci, Staphylococcus aureus, microbial interaction, bovine mastitis, protective effect

\section{INTRODUCTION}

Today, non-aureus staphylococci (NAS) are the most common cause of bovine IMI in dairy herds worldwide (Braem et al., 2013; Souza et al., 2016). When studying NAS, aggregating NAS as a group without accurate species identification is no longer recommended because species-specific differences in behavior, epidemiology, ecology, and effect on udder health have been revealed (Vanderhaeghen et al., 2014). Furthermore, NAS species showed great differences in antimicrobial susceptibility and virulence factors (Sawant et al., 2009). Condas et al. (2017) concluded that considering NAS as a single group has undoubtedly contributed to apparent discrepancies among studies as to their distribution and importance in IMI. 
Previous studies have extensively investigated the epidemiological characteristics of NAS for dairy herds with conventional milking systems. However, knowledge about these characteristics or patterns is sparse for dairy cows in automatic milking systems (AMS; Supré et al., 2011; De Visscher et al., 2014). Management of udder health in conventional milking systems differs from AMS (Dohmen et al., 2010; Hovinen and Pyörälä, 2011). Cows in AMS can be milked up to 5 times daily without any human contact with the udder. The longer milking duration and exposure of the teat skin to disinfectants may affect the teat skin microbiota. Furthermore, risk is high for teat colonization and subsequently IMI because up to 60 cows are milked several times daily with the same robot (Rasmussen, 2006).

The epidemiological and ecological characteristics NAS isolated from milk and surrounding environment of cows differ and are associated with the identified species. Results from research studies on NAS are sometimes conflicting. Vanderhaeghen et al. (2015) reported that $S$. chromogenes is a bovine-adapted species involved in many cases of IMI, and Staphylococcus simulans typically causes contagious IMI, whereas Staphylococcus xylosus appears to be a versatile species. The NAS species originating from distinct habitats showed clear differences that may be related to their diversity in ecology and epidemiological behavior (Souza et al., 2016). These different and contradictory results about NAS characteristics may likely be due to the lack of knowledge about their ecology and epidemiology within and between species (Fry et al., 2014). Therefore, extra efforts are crucial to improve our knowledge on different traits of NAS at the species level in the different habitats for boosting our understanding of their epidemiology in dairy herd context.

The effects of NAS on the risk of acquiring Staphylococcus aureus IMI have yielded ongoing debate (Reyher et al., 2012; Vanderhaeghen et al., 2014). Using traditional antibiotics is the most common approach for treatment of $S$. aureus infections and bovine mastitis in general. However, this approach is associated with adverse consequences including emergence of bacterial resistance and antimicrobial residues in milk (Gomes and Henriques, 2016). Therefore, finding effective nonantibiotic antimicrobials and alternative strategies to substitute the administration of antibiotics for mastitis treatment and control is vital. Painter et al. (2014) reported that the ability of $S$. aureus to cause a wide range of infections has been ascribed to its armory of various virulence factors, many of which are under the control of the quorum-sensing accessory gene regulator (agr) system of S. aureus. Singh and Ray (2014) demonstrated that agr plays a central role in staphylococcal pathogenesis. The agr system is composed of a 2-component signal transduction system that in response to a secreted auto-inducing peptide (AIP) controls virulence gene expression depending on cell density. At low cell density, cell-surface-associated adhesion factors are produced, whereas at high cell density hemolysins and other secreted virulence factors are expressed (Le and Otto, 2015). Originally, the agr system was considered only to monitor the presence of $S$. aureus cell densities, but several studies have documented that other staphylococcal species produce AIP-like molecules, which inhibit $S$. aureus agr and toxin production (Otto et al., 2001; Canovas et al., 2016; Paharik et al., 2017). Therefore, knowledge of the microbial interactions between a variety of NAS species originating from dairy cows and dairy environment on the one hand, and S. aureus on the other hand, may ultimately lead to new ways of controlling infections with $S$. aureus. To the best of our knowledge, no literature is available that has investigated the cross-talk between agr quorum system of $S$. aureus and NAS isolated from milk as well as teat skin habitats of dairy cows at species level of NAS. The objectives of this study were to (1) investigate the distribution patterns of NAS species on quarter level from aseptic milk and teat skin samples in dairy herds with AMS, and (2) examine if the isolated NAS influences the expression of $S$. aureus virulence factors controlled by the agr quorum sensing system.

\section{MATERIALS AND METHODS}

\section{Study Population}

Eight dairy herds with Danish Holstein cows were selected for participation in a project on Streptococcus agalactiae and Staphylococcus aureus IMI. The herds had to have AMS with $\geq 3$ milking robots and bulk tank milk PCR cycle threshold value $\leq 32$ for Streptococcus agalactiae. About 30 to 40 lactating dairy cows were selected randomly from each herd based on the criteria of having no clinical mastitis, having SCC $\geq 200,000$ cells/ $\mathrm{mL}$ at the previous milk recording, and not having been treated with antimicrobials during 4 wk before sample collection. Teat skin swab and aseptic foremilk samples were collected from all quarters of selected cows. In the current study, samples from right hind and left front quarters of cows with an odd laboratory running number were included. Herd management practices and characteristics are listed in Table 1.

\section{Sampling Procedures}

Each herd was visited once to collect teat swab samples and aseptic quarter foremilk samples for bacte- 
MAHMMOD ET AL.

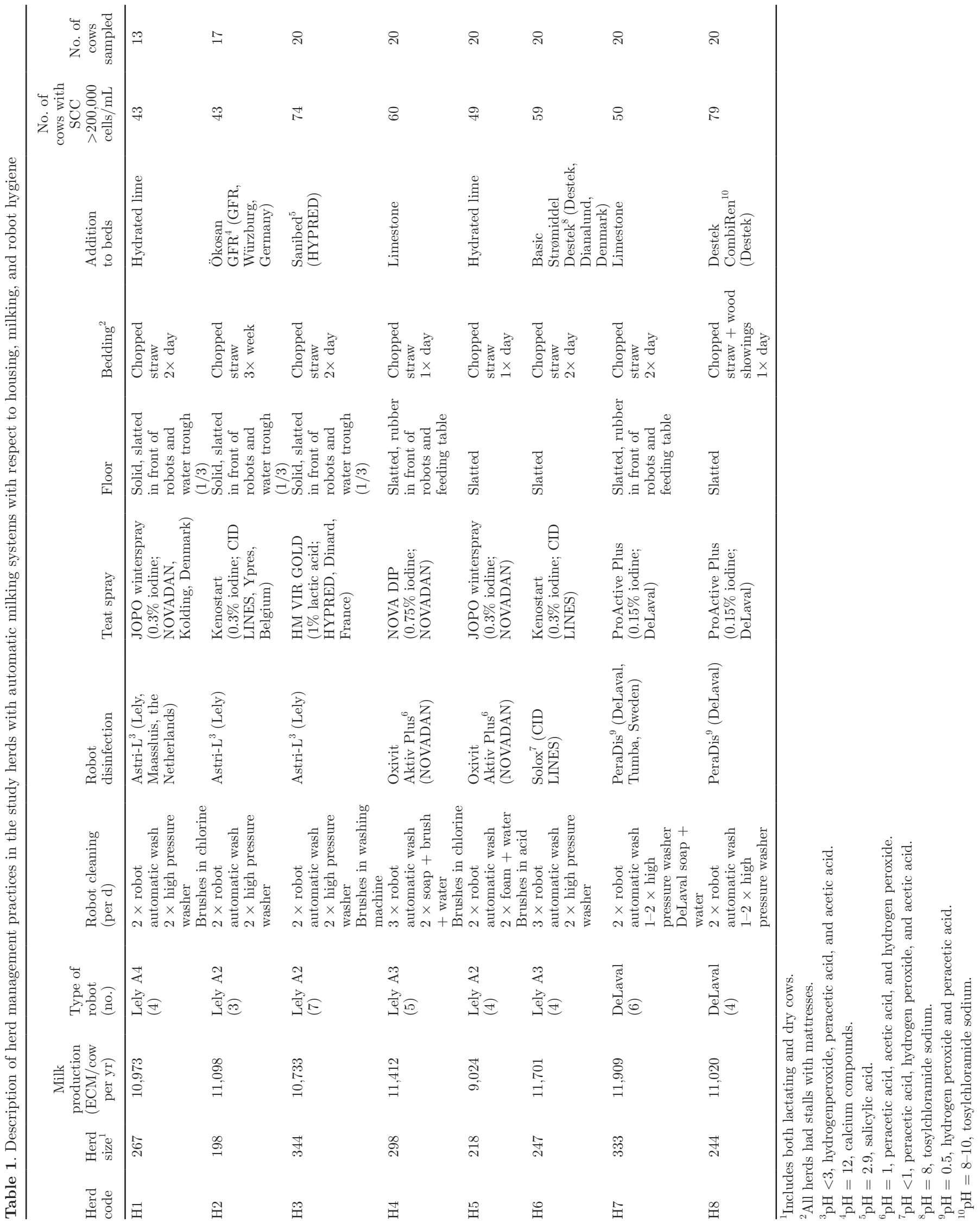


rial culture. The farmers were asked to separate the selected cows, and the cows were fixed in head lockers or tied. Teat swab samples were collected according to the modified wet-dry method (Paduch et al., 2013). Briefly, the teat skin was sampled after cleaning with dry tissue paper. The first swab (Dakla Pack) was moistened with 1/4 Ringer's solution (Oxoid, Roskilde, Denmark) and rotated $360^{\circ}$ around the teat about $1 \mathrm{~cm}$ from the teat canal orifice. The same procedure was carried out with the dry swab. Immediately after sampling, the tips of both swabs were transferred into 1 tube with $2 \mathrm{~mL}$ of sterile Ringer's solution.

Quarter milk samples were collected directly after harvesting the teat swab samples according to National Mastitis Council (1999) guidelines. Briefly, the teat end was thoroughly disinfected with cotton swabs drenched with ethanol (70\%). Individual quarter foremilk samples were then aseptically collected in sterile screw-cap plastic tubes. New latex gloves were worn for each sampling procedure and each cow. Tubes containing the teat swabs and aseptic milk samples were stored in ice boxes and delivered to the microbiological laboratory within $12 \mathrm{~h}$. All study activities including farm visits, collection of samples, and laboratory examination were carried out during the period from February to May 2017.

\section{Laboratory Procedures}

Bacterial Culture and MALDI-TOF Assay. Bacterial culture for milk samples was conducted in accordance with National Mastitis Council (1999) recommendations. After vortexing, $0.01 \mathrm{~mL}$ of the milk sample from each quarter was streaked using disposable calibrated inoculating loops on a quarter of a calf blood agar, and another $0.01 \mathrm{~mL}$ was streaked on a quarter of a chromogenic agar selective for Staphylococcus species (SaSelect, Bio-Rad, Marnes-la-Coquette, France) and incubated at $37^{\circ} \mathrm{C}$ for $48 \mathrm{~h}$ (Dolder et al., 2017). Bacterial culture of teat swab samples was performed according to the procedures of Paduch et al. (2013). Briefly, the teat swab samples were vortexed before removing the swab tips from the tubes. The agar plates were inoculated with $0.1 \mathrm{~mL}$ of the swab solution. The inoculum was spread with a sterile Drigalski spatula onto the whole calf blood agar and SaSelect agar for each quarter and were incubated at $37^{\circ} \mathrm{C}$ for $48 \mathrm{~h}$.

Staphylococci species were identified on blood agar based on the phenotypic characteristics of their colonies including shape (round, glossy) according to according to National Mastitis Council (2004) guidelines and their color on the selective medium according to the manufacturer's instructions (SaSelect). We considered only quarter milk samples and teat skin swabs having 3 different Staphylococcus species per sample for further identification at species level. Cut-off $\geq 5$ cfu on the plate was regarded as an acceptable cutoff point for definition of NAS IMI and NAS colonization of the teat apex (Thorberg et al., 2009).

All isolates of NAS species that were identified on bacterial culture were subcultured on calf blood agar and incubated for $24 \mathrm{~h}$ at $37^{\circ} \mathrm{C}$ to be submitted freshly to MALDI-TOF (Microflex LT, Bruker Daltonics GmbH, Bremen, Germany) for identification. The MALDI-TOF assay was conducted according to the manufacturer's instructions and Cameron et al. (2017), and all isolates were tested in triplicate. After 2 submissions to MALDI-TOF, the unidentified isolates were considered as "no possible identification." Cut-point threshold $\geq 1.7$ was regarded as an acceptable and reliable threshold for identification of NAS species (Cameron et al., 2017). All identified NAS species isolates were stored in a sterile $10 \%$ glycerol solution at $-80^{\circ} \mathrm{C}$ for future use.

Qualitative Beta-Galactosidase Reporter Plate Assay. To examine if the NAS influence the expression of $S$. aureus virulence factors controlled by the agr quorum sensing system, a set of the identified NAS species was selected to represent all the identified species in milk and teat skin samples from the 8 herds. The NAS isolates were selected to represent all the identified NAS species $(\mathrm{n}=16)$ and to represent NAS isolates from milk and teat skin. Staphyloccus aureus strain 8325-4 (Novick, 1967), which represented agr type I, was used as a source of AIP-I-containing supernatant. For the $\beta$-galactosidase plate assays PC203 (S. aureus 8325-4, spa::lacZ), PC322 (S. aureus 8325-4, hla::lacZ), SH101F7 (S. aureus 8325-4, rnaIII::lacZ; Chan and Foster, 1998; Canovas et al., 2016) were used. Strain 2898 of Staphylococcus schleiferi (positive control) was used to produce a supernatant that inhibits agr activity (Canovas et al., 2016), whereas 8325-4 (AIP-I) supernatant was used to induce agr. The reporter assays and analysis of supernatants of NAS cultures were conducted as described by Nielsen et al. (2010) and Canovas et al. (2016). Briefly, bacteria (S. aureus) were grown on tryptone soy agar (TSA) plates containing erythromycin $(5 \mu \mathrm{g} / \mathrm{mL})$, and the $\beta$-galactosidase substrate, 5 -bromo-4-chloro-3-indolyl- $\beta$-D-galactopyranoside (XGal; $150 \mu \mathrm{g} / \mathrm{mL}$ ). Overnight cultures were made by inoculating a single colony into $10 \mathrm{~mL}$ of tryptone soy broth in a glass vial and shaken vigorously ( $\sim 200 \mathrm{rpm})$ at $37^{\circ} \mathrm{C}$ overnight $(16 \mathrm{~h})$. Dilutions in $\mathrm{NaCl}$ were made from each overnight culture. About $1,000 \times$ dilution was used where the optical density at $600 \mathrm{~nm}$ of the $10 \times$ dilution adjusted to 0.35 before diluting then further to 0.0035 . The TSA was melted and cooled down in 
a water bath for approximately $45 \min$ to $45^{\circ} \mathrm{C}$ where X-gal $(150 \mu \mathrm{g} / \mathrm{mL})$ and erythromycin $(5 \mu \mathrm{g} / \mathrm{mL})$ were added. About $2 \mathrm{~mL}$ dilution of cells was mixed with 50 $\mathrm{mL}$ of medium in Greiner plates. After the cells and the medium were mixed well, the plates were allowed to stand on the table to harden and dried in a laminar air flow bench (Esco Gb Ltd., Barnsley, UK) for $45 \mathrm{~min}$. In total, 16 wells (14 test isolates plus one positive and one negative controls, Figure 1) were made manually with a sterile sharp iron drill to make a ring-shaped cut through the agar. The small piece of agar in the middle of the ring was then removed using a sterile scalpel. About $20 \mu \mathrm{L}$ of cell-free supernatants of the test NAS strains were added to wells formed in TSA plates containing reporter strains carrying lacZ fusions to either one of the agr-controlled virulence genes hla, spa, or RNAIII as well as the $\beta$-galactosidase substrate and X-Gal. The plates were incubated at $37^{\circ} \mathrm{C}$ for approximately 9 to $36 \mathrm{~h}$ until the blue color appeared on the plate. Downregulation was rated according to the presence or absence of the inhibition halo zone around the well. No zone means no effect, whereas the presence of an inhibition halo zone indicates a downregulation effect, and the degree of effect depends on the diameter of inhibition zone, ranging from a slight effect to severe effect.

To obtain cell-free supernatants of the test strains, an overnight culture of the selected NAS strains was prepared, and on the following day, about $2 \mathrm{~mL}$ of the cell culture in an Eppendorf tube was spun in a tabletop centrifuge at $7,155 \times g$ at $4^{\circ} \mathrm{C}$ for $3 \mathrm{~min}$. We took $20 \mu \mathrm{L}$ of each cell-free supernatant and placed it into the respective well.

\section{Statistical Analyses}

To investigate if teat apex colonization with a specific NAS species increased the odds of IMI with the given species in the corresponding quarter, a logistic mixed regression model with herd and cow treated as random intercept was used. Different models were therefore performed for each of the NAS IMI species recovered from the quarter milk samples. Statistical analysis was carried out in $\mathrm{R}$ version 3.3.3 (The R Foundation for Statistical Computing, Vienna, Austria). Results for all analyses were considered significant at a $P$-value $\leq 0.05$.

\section{RESULTS}

\section{NAS Species in Milk and Teat Skin and Their Association}

Out of 150 cows considered in this study, 8 cows were excluded for having dry quarters $(\mathrm{n}=16)$. In total, $80 \%(228 / 284)$ quarters from 142 cows harbored at least one NAS species. In total, MALDI-TOF identified
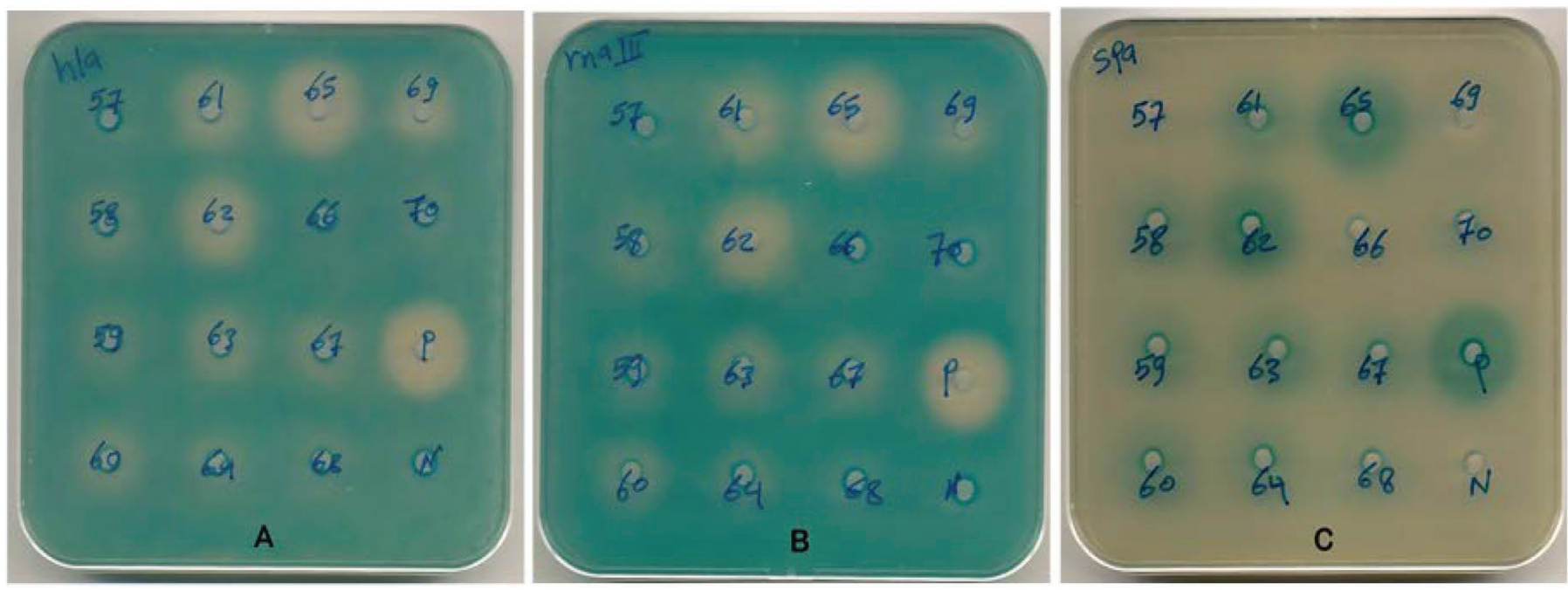

Figure 1. Modulation of Staphylococcus aureus virulence gene expression by non-aureus staphylococcal culture supernatants. Tryptone soy agar plates (with erythromycin and X-gal) containing (A) the hla-lacZ (PC322; Eryr), (B) the rnaIII-lacZ (SH101F7; Ery ${ }^{\mathrm{r}}$ ), or (C) the spa-lacZ $\left(\mathrm{PC} 203 ;\right.$ Ery $\left.^{\mathrm{r}}\right)$ reporter strain of Staphylococcus aureus were exposed to $20 \mathrm{~mL}$ (in predrilled wells) of supernatants from centrifugation (7,155 $\times g$ for $60 \mathrm{~s}$ ) of overnight cultures of strains 57 (Staphylococcus equorum), 58 (Staphylococcus epidermidis), 59 (Staphylococcus piscifermentans), 60 (Staphylococcus xylosus), 61 (Staphylococcus chromogenes), 62 (Staphylococcus arlettae), 63 (Staphylococcus haemolyticus), 64 (Staphylococcus piscifermentans), 65 (Staphylococcus arlettae), 66 (Staphylococcus sciuri), 67 (Staphylococcus haemolyticus), 68 (Staphylococcus xylosus), 69 (Staphylococcus haemolyticus), and 70 (Staphylococcus cohnii). P (positive control): strain 2898 of Staphylococcus schleiferi. N (negative control): $\mathrm{NaCl}$. Zones appeared between 9 and $36 \mathrm{~h}$ of incubation at $37^{\circ} \mathrm{C}$. This figure is representative of one set of screening plates. Color version available online. 
Table 2. Species distribution and association of non-aureus staphylococci (NAS) isolates from aseptic quarter milk and teat skin samples collected from 142 cows (284 quarters) in 8 dairy herds with automatic milking systems

\begin{tabular}{|c|c|c|c|c|}
\hline \multirow[b]{2}{*}{ NAS species ${ }^{1}(\mathrm{n})$} & \multicolumn{2}{|c|}{ Sample type, no. (\%) } & \multirow[b]{2}{*}{$\mathrm{OR}^{2}(95 \% \mathrm{CI})$} & \multirow[b]{2}{*}{$P$-value } \\
\hline & Milk $(\mathrm{n}=105)$ & Teat $(\mathrm{n}=268)$ & & \\
\hline Staphylococcus capitis (3) & - & $3(1.1)$ & - & - \\
\hline Staphylococcus chromogenes (16) & $11(10.5)$ & $5(1.9)$ & 7.6e-1 (NA-2.4e+7) & 0.85 \\
\hline Staphylococcus cohnii (43) & $5(4.8)$ & $38(14.2)$ & $2.23(0.11-15.6)$ & 0.48 \\
\hline Staphylococcus epidermidis (60) & $52(49.5)$ & $8(3.0)$ & $0.88(0.05-5.07)$ & 0.90 \\
\hline Staphylococcus hominis (17) & $3(2.9)$ & $14(5.2)$ & - & - \\
\hline Staphylococcus piscifermentans (2) & - & $2(0.8)$ & - & - \\
\hline Staphylococcus saprophyticus (5) & - & $5(1.9)$ & - & - \\
\hline Staphylococcus sciuri $(9)$ & - & $9(3.4)$ & - & - \\
\hline Staphylococcus simulans (2) & $2(1.9)$ & - & - & - \\
\hline Staphylococcus succinus (2) & - & $2(0.8)$ & - & - \\
\hline Staphylococcus vitulinus (1) & - & $1(0.4)$ & - & - \\
\hline
\end{tabular}

${ }^{1}$ Staphylococcus arlettae, S. warneri, and S. hominis were not considered in the statistical analysis because of the low number of observations $(<5)$, whereas S. capitis, S. piscifermentans, S. saprophyticus, S. sciuri, S. simulans, S. succinus, and S. vitulinus were not isolated from milk or teat skin.

${ }^{2} \mathrm{OR}=$ odds ratio $; \mathrm{NA}=$ not available.

16 different NAS species. Out of these 16 species, 15 species were identified from teat skin, whereas only 10 species were identified from milk and 9 species were identified from both sites (Table 2).

From milk, 105 isolates of NAS were identified from 94 quarters of 47 cows, whereas 268 isolates were identified on the teat skin of 190 quarters of 95 cows. The number of quarters with mixed (coinfections) infections (colonization or IMI) of NAS species (at least 2 different species) in teat skin swabs samples $(37 \%, 70 / 190)$ was higher than the number of quarters with mixed infections in milk $(12 \%, 11 / 94)$. Staphylococcus equorum and Staphylococcus haemolyticus were the most common combination of mixed NAS in teat skin $(\mathrm{n}=$ 21 quarters), whereas milk had no specific combination pattern but Staphylococcus epidermidis was the most common partner $(\mathrm{n}=6$ quarters). Additionally, 18 isolates of $S$. aureus were identified as coinfections with the different NAS species from milk $(\mathrm{n}=4)$ and teat skin $(\mathrm{n}=14)$ samples (Table 3$)$.

The most prevalent NAS species identified from milk were $S$. epidermidis $(50 \%, 52 / 105), S$. haemolyticus $(15 \%, 16 / 105)$, and S. chromogenes (11\%, 11/105), accounting for $76 \%$ of all NAS isolates from milk. On the other hand, the most identified NAS species from teat skin were S. equorum $(43 \%, 116 / 268)$, S. haemolyticus $(15.7 \%, 42 / 268)$, and S. cohnii $(14.2 \%, 38 / 268)$, accounting for $73 \%$ of all NAS isolates from teat skin. Remarkably, 6 NAS species including $S$. capitis, $S$. sciuri, S. succinus, S. vitulinus, S. saprophyticus, and S. piscifermentans were not shown in milk, whereas
S. simulans was the only NAS species that was not isolated from teat skin.

Distribution of NAS species varied among the 8 herds (H1-H8) in both milk and teat skin samples. Staphylococcus equorum was the most prevalent species in $\mathrm{H} 1 \quad(92 \%, 11 / 12), \mathrm{H} 2(58 \%, 15 / 26), \mathrm{H} 3(35 \%$, $16 / 46), \mathrm{H} 4(47 \%, 23 / 49), \mathrm{H} 5(34 \%, 24 / 70)$, and $\mathrm{H} 6$ $(29 \%, 21 / 72)$, whereas $S$. haemolyticus was the most prevalent species in $\mathrm{H} 7(22 \%, 9 / 41)$ and $S$. cohnii in $\mathrm{H} 8$ $(44 \%, 25 / 57)$. Teat apex colonization with $S$. equorum significantly increased the odds of having IMI with $S$. equorum (Table 2). Isolation of $S$. chromogenes, $S$. cohnii, S. epidermidis, S. haemolyticus, and S. xylosus from teat skin was not found to increase odds of IMI for these NAS species.

\section{Microbial Interactions of NAS Species with S. aureus}

Out of the total identified NAS isolates $(\mathrm{n}=373)$, 81 isolates (32 milk and 49 teat skin), representing 16 different species from 58 dairy cows were selected to examine their ability to interfere with the agr quorum sensing system of $S$. aureus. In 58 (71.6\%), 55 (67.9\%), and $49(60.5 \%)$ out of 81 of the staphylococcal supernatants of the tested NAS isolates, we observed reduced expressions of hla, RNAIII, and spa, respectively (Figure 1; Table 3), indicating that NAS species interfere with the agr quorum sensing system of $S$. aureus.

The NAS isolates of the same species from different herds showed different patterns on the agr quorum sensing system of $S$. aureus. For example, isolates of $S$. 
MAHMMOD ET AL.

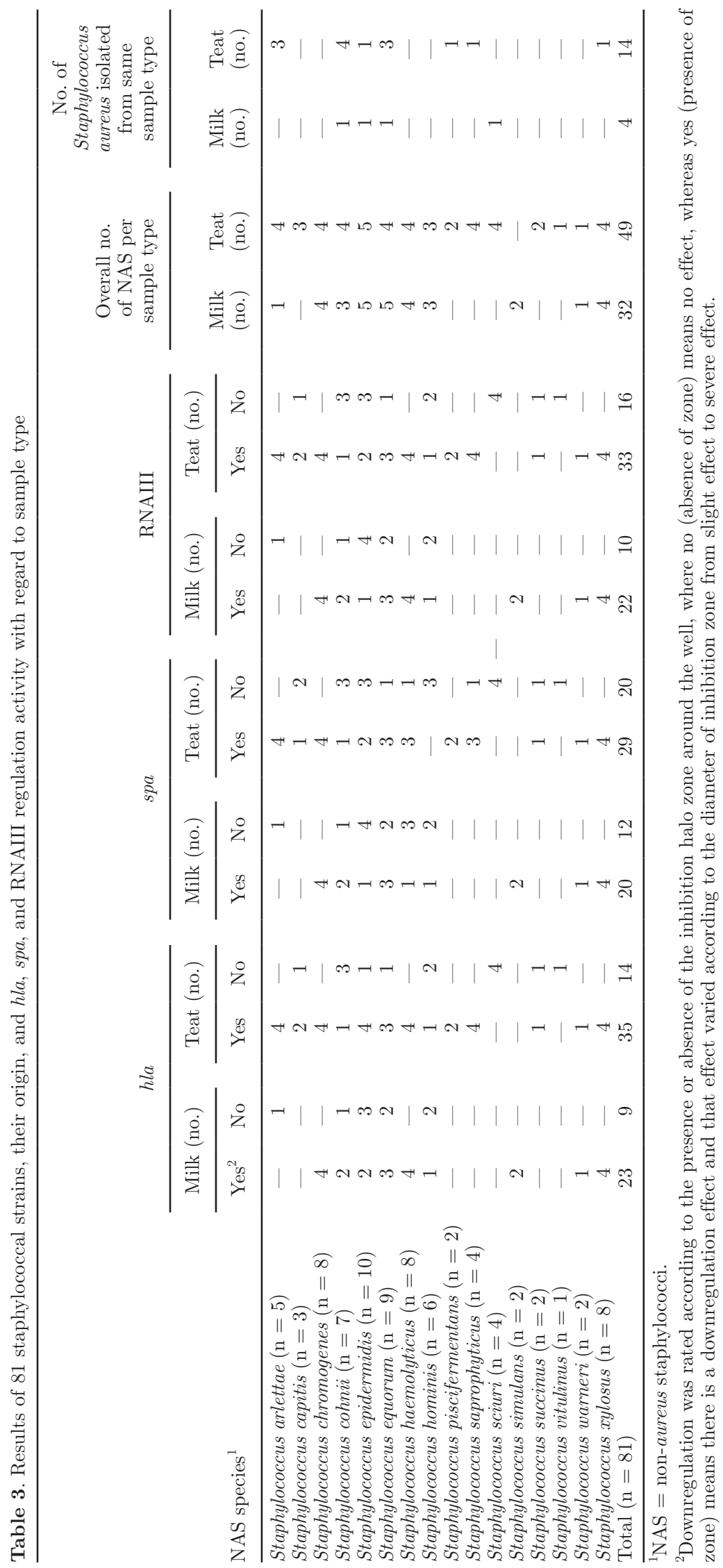


equorum from milk of $\mathrm{H} 1, \mathrm{H} 3$, and $\mathrm{H} 5$ downregulated the agr quorum sensing system of $S$. aureus, whereas $S$. equorum isolates from $\mathrm{H} 2$ and $\mathrm{H} 5$ had no effect indicating the important role of herd characteristics and management on the pattern of microbial interactions.

The pattern of cross-talk between NAS species and $S$. aureus virulence gene varied according to the involved NAS species. Our NAS isolates showed 3 main different patterns: (1) downregulation effect represented by S. chromogenes (milk), S. simulans (milk), S. xylosus (milk and teat), S. saprophyticus (teat), S. warneri (milk and teat), S. haemolyticus (milk and teat), $S$. piscifermentans (teat), and S. arlettae (teat), (2) no effect represented by S. sciuri (teat) and Staphylococcus vitulinus (teat). The third pattern (3), variable effect, was represented by $S$. epidermidis (milk and teat), $S$. equorum (milk and teat), S. hominis (milk and teat), $S$. cohnii (milk and teat), and S. succinus (teat; Table 3).

\section{DISCUSSION}

To the best of our knowledge, this is the first study describing the distribution patterns of NAS species on the quarter level from milk and teat skin in dairy herds with AMS. Furthermore, we have demonstrated for the first time the microbial interactions and cross-talk between different NAS species isolated from milk and teat skin, and $S$. aureus as mediated via the agr quorum sensing system and the resulting pattern on aspects of virulence and colonization of $S$. aureus.

\section{NAS Species from Milk and Teat Skin and Their Association}

We have identified 10 out of 16 NAS species in milk, where S. epidermidis, S. haemolyticus, and S. chromogenes were most frequently isolated, confirming their major role in causing IMI in dairy herds with AMS. This comes in agreement with the findings of previous studies (Piessens et al., 2011; Dolder et al., 2017; Condas et al., 2017). However, other studies have reported different predominant NAS species associated with bovine IMI (Supré et al., 2011; Fry et al., 2014). De Visscher et al. (2016a) concluded that S. chromogenes, S. sciuri, and S. cohnii were the predominant species causing IMI in freshly calved heifers and dairy cows. These variations among the findings of different studies could be caused by the differences in study design, type of milking system, species identification methods and criteria of IMI definition, different herd management, and species-specific characteristics of NAS (Zadoks and Watts, 2009).

Concerning the teat apex colonization, we identified 15 out of 16 identified NAS species with different fre- quencies. However, S. equorum, S. haemolyticus, and $S$. cohnii were identified as the most commonly isolated NAS species from teat skin across the 8 herds. This finding indicates that teat skin is a natural habitat for a wider range of NAS species in comparison to those species found in milk, which could indicate that not all NAS species are adapted to the milk habitat or were equally able to invade the teat canal. In line with this statement, 6 NAS species including S. capitis, S. sciuri, S. succinus, S. vitulinus, S. saprophyticus, and S. piscifermentans have never been shown in milk, whereas $S$. simulans was the only NAS species to never have been isolated from teat skin. Falentin et al. (2016) reported that Staphylococcus was the dominant genus in the bovine teat microbiota (an average abundance of $23.8 \%$ ) with $S$. equorum and $S$. aureus as the most commonly identified species $(\sim 13 \%)$ of staphylococci. Therefore, the wide range of NAS species could actually be part of the normal microbiota of the teat skin.

Our findings are comparable to the findings of previous studies, which isolated NAS from teat apex (Piessens et al., 2011; De Visscher et al., 2014, 2016b). This is consistent with Braem et al. (2013), who found that S. equorum and S. haemolyticus were the most prevalent NAS species on teat skin. Similarly, De Visscher et al. (2014) reported that the most prevalent species in the parlor-related extramammary niches were S. cohnii, $S$. fleurettii, and S. equorum in herds 1 to 3, respectively, whereas $S$. haemolyticus and $S$. sciuri were present in all herds. Based on phenotyping, Taponen et al. (2008) found S. equorum and S. sciuri, and based on ribotyping, S. succinus and S.xylosus, as the predominant NAS species in extramammary samples (udder skin, teat apices, and teat canals) of lactating dairy cows of 1 herd.

The distribution of NAS species differed widely across the 8 herds. For instance, S. arlettae and S. sciuri were the most prevalent species in H7, whereas S. haemolyticus and $S$. chromogenes were the most prevalent species in H5. This marked variation in the distribution of NAS species across the study herds could indicate that the NAS distribution is herd specific. Similar findings were reported by Dolder et al. (2017) from Switzerland and Condas et al. (2017) from Canada. Species-specific characteristics of NAS, herd-specific management, and study design could be possible explanations for the difference in species distribution between studies and herds. As shown in Table 1, our study herds showed different management practices in respect to type and management of robot, teat spray, and robot disinfection, type of bedding, and floor. Similar findings were reported in conventional dairy herds by De Visscher et al. (2014), who reported that $S$. cohnii was common on both teat apex and in milk, whereas $S$. haemolyticus in 
$\mathrm{H} 1, S$. fleurettii in $\mathrm{H} 2$, and S. equorum in $\mathrm{H} 3$ were more common on the teat apex than in milk.

Teat apex colonization with S. equorum increased the odds of IMI in the same quarter; however, we could not find such significant association for other species such as $S$. chromogenes, S. cohnii, S. epidermidis, $S$. haemolyticus, and S. xylosus. A similar findings have been reported by previous studies (Piepers et al., 2011; Quirk et al., 2012; Braem et al., 2013). Quirk et al. (2012) found that S. cohnii was the only NAS that did not concurrently cause IMI and colonize the teat canal. Therefore, interchange between NAS species colonizing the teat skin and causing IMI is possible but that could be characteristic for specific NAS species (Adkins et al., 2018). De Visscher et al. (2014) found a relationship between detection of NAS on teat apex and in milk, but could not determine the direction of the relationship. In other words, we do not know if NAS in milk originates from the teat skin or if the teat skin is colonized because of intramammary shedding of NAS. Dolder et al. (2017) suggested that the possible causes for a positive association might be a combination of distinct virulence factors, synergism in bacteria metabolism, and environmental conditions such as poor hygiene; however, the true underlying mechanisms remain unclear.

\section{Microbial Interactions of NAS Species with S. aureus}

Previous studies have documented the agr crossinhibition between $S$. aureus and other staphylococcal species mainly of human and nonbovine origin leading to an inhibition of the secreted virulence factors including major toxins such as $\alpha$-hemolysin and the phenole soluble modulins (Otto et al., 2001; Canovas et al., 2016; Paharik et al., 2017). Our study confirms that similar patterns of microbial interactions exist between NAS species isolated from different habitats in dairy cows and S. aureus. Several staphylococcal species had the ability of cross-interfering with the $S$. aureus agr quorum sensing system. These findings could be highly relevant to understand the role of NAS in udder health and may explain conflicting results reported from NAS in previous studies. Some studies reported that presence of NAS in the same habitat (e.g., milk) would provide a protective effect against IMI with $S$. aureus (De Vliegher et al., 2004; Piepers et al., 2011; Vanderhaeghen et al., 2014). Dos Santos Nascimento et al. (2005) reported that some NAS species from milk can produce antimicrobial substances called bacteriocins inhibiting the growth of some major mastitis pathogens, including S. aureus. Recently, Goetz et al. (2017) reported that isolates of $S$. chromogenes and S. simulans significantly reduced biofilm formation in approximately $80 \%$ of the staphylococcal species tested, including $S$. aureus. Furthermore, previous studies confirmed the protective role of $S$. chromogenes against IMI with $S$. aureus (Matthews et al., 1990; De Vliegher et al., 2003, 2004).

Other research studies could not demonstrate a protective effect of NAS against major pathogens including S. aureus (Vanderhaeghen et al., 2014) or S. aureus and S. uberis (Zadoks et al., 2001). Previous reports showed that presence of NAS increased the odds of having a new S. aureus IMI (Parker et al., 2007; Reyher et al., 2012). In the current study, we have shown different patterns for different NAS species including NAS distribution within AMS herds and sample type variation. These different patterns could offer one or more explanation for the findings of the previous studies on NAS epidemiology and characteristics. We want to highlight an important point of difference between our findings and previous studies. Most of the previous studies investigated the relationship and interaction between $S$. aureus and NAS species based specifically on the aspect of antimicrobial interaction where NAS act by producing antimicrobial compounds that eliminate $S$. aureus from the surrounding environment (De Vliegher et al., 2004; dos Santos Nascimento et al., 2005). Meanwhile, our unique findings were based exclusively on investigation of the crosstalk between S. aureus and NAS species via examining the influence of NAS species on the expression of $S$. aureus virulence factors controlled by agr quorum sensing system.

For some species, all isolates (e.g., S. chromogenes, S. xylosus, S. simulans, and S. saprophyticus) repressed agr activity to some degree, whereas for other species (e.g., S. epidermidis, S. equorum, S. hominis, and $S$. cohnii) only some of the isolates produced an agr inhibitory activity in culture supernatants. Although we do not know the exact mechanism of repression in these isolates, but we anticipate that they produce AIP-like molecules that inhibit the $S$. aureus quorum sensing system. Canovas et al. (2016) demonstrated that $S$. schleiferi produce an AIP variant that has very strong agr repressing activity. However, in that study the staphylococcal species originated from different animal host species such as dog, horse, cow, bird, and cat. Some NAS species are common to many hosts such as $S$. epidermidis, S. haemolyticus, S. saprophyticus, $S$. simulans, and $S$. xylosus. Other NAS species such as $S$. caprae, S. chromogenes, S. felis, S. gallinarum, and $S$. schleiferi are the most common species in small ruminants (Pengov, 2001), cattle (Carretto et al., 2005; Condas et al., 2017), cats (Lilenbaum et al., 1999), chickens (Aarestrup et al., 2000), and dogs (Penna et al., 2010), respectively, whereas they are rare in other host species. Here, we show that NAS species found on teat 
skin and in milk of dairy cattle also have the potential of repression agr activity. Our findings indicate that NAS species originating from the teat skin environment numerically appear to be more likely repressive to $S$. aureus, which has to be confirmed with a larger sample size and further investigation. It was reported that crosstalk involving agr interference has been observed as a result of co-habitual competition within the same ecological niche (Condas et al., 2017). In this study, we have identified 14 quarters harbor different NAS species having co-existence with $S$. aureus from milk (n $=4)$ and from teat $(\mathrm{n}=14)$. Therefore, we speculate that the observed crosstalk may be explained partially by the co-habitual competition between $S$. aureus and NAS species within the same niche.

The selection criteria for the study herds and inclusion criteria of dairy cows and quarters should be taken in mind in terms of the generalizability of the obtained findings. We investigated NAS of cows with elevated SCC in AMS herds, which could differ from NAS derived from cows with low SCC or cows milked in other milking systems. In other words, AMS herds may have different NAS species with different characteristics compare with conventional milking systems. That could be argued by the no human contact to the udder tissue under AMS environment. Moreover, cows are milked several times (up to 5) daily with the same robot (Rasmussen, 2006). As the effect of NAS on SCC is species specific (Supré et al., 2011; Fry et al., 2014) with higher SCC reported from S. chromogenes and $S$. simulans (Fry et al., 2014), we may have selected for specific NAS species with more pronounced effect on SCC. The finding of interactions between $S$. aureus and different NAS species causing IMI or colonizing teat skin of dairy cows (or both) opens the door for identification of new and effective nonantibiotic anti-virulence strategies targeting $S$. aureus infections as alternative to antimicrobials or biocides used for $S$. aureus mastitis treatment and control. Further studies are necessary in the future such as field studies with larger sample sizes and additional assays of NAS species isolates (e.g., quantitative $\beta$-galactosidase reporter plate assay to identify and quantify the cross-talk patterns between $S$. aureus and different NAS species).

\section{CONCLUSIONS}

In total, 15 different NAS species were identified from teat skin, whereas 10 species were identified from milk. Staphylococcus epidermidis, S. haemolyticus, and $S$. chromogenes were the most prevalent species in milk, accounting for $76 \%$, whereas $S$. equorum, $S$. haemolyticus, and $S$. cohnii were the most prevalent species in teat skin, accounting for $73 \%$. Staphylococcal supernatants of NAS species isolated from milk and teat skin interfered with the agr quorum sensing system of $S$. aureus. The pattern of cross-talk between NAS species and $S$. aureus virulence gene expression varied according to the involved NAS species. Our NAS isolates showed 3 patterns: (1) downregulation effect [e.g., S. chromogenes (milk)], (2) no effect [e.g., S. sciuri (teat)], and (3) variable effect [e.g., S. epidermidis (milk and teat)]. The NAS species, habitat type, and herd factors affect NAS and S. aureus crosstalk patterns. The findings of this study will boost our knowledge and understanding of the epidemiology of NAS species and their relation with $S$. aureus IMI, colonization of teat skin of dairy cows, or both.

\section{ACKNOWLEDGMENTS}

The study was part of the research project STOPMAST financed by the Danish Milk Levy Foundation (Aarhus, Denmark). We gratefully acknowledge the efforts of Nanna Skjølstrup and Louise Mathiasen (Department of Veterinary and Animal Sciences, University of Copenhagen, Frederiksberg C, Denmark) for their help with sampling and examination of samples by bacterial culture. We also thank Bettina Nonnemann (National Veterinary Institute, Technical University of Denmark, Kongens Lyngby, Denmark) for conducting the MALDI-TOF assay. Thanks to the Danish farmers for their help and making their cows available for our study. Thanks to the milk quality technicians at SEGES (Aarhus, Denmark) helping taking milk samples and to the laboratory technicians at Technical University of Denmark and University of Copenhagen for their technical and logistic support. Yasser Mahmmod was supported by the Islamic Development Bank Merit Scholarship Program (IDB-MSP), Jeddah, Saudi Arabia.

\section{REFERENCES}

Aarestrup, F. M., Y. Agers $\varnothing$, P. Ahrens, J. C. Jorgensen, M. Madsen, and L. B. Jensen. 2000. Antimicrobial susceptibility and presence of resistance genes in staphylococci from poultry. Vet. Microbiol. 74:353-364.

Adkins, P. R. F., S. Dufour, J. N. Spain, M. J. Calcutt, T. J. Reilly, G. C. Stewart, and J. R. Middleton. 2018. Molecular characterization of non-aureus Staphylococcus spp. from heifer intramammary infections and body sites. J. Dairy Sci. https://doi.org/10.3168/jds .2017-13910. In press.

Braem, G., S. De Vliegher, B. Verbist, V. Piessens, E. Van Coillie, L. De Vuyst, and F. Leroy. 2013. Unraveling the microbiota of teat apices of clinically healthy lactating dairy cows, with special emphasis on coagulase-negative staphylococci. J. Dairy Sci. 96:1499-1510.

Cameron, M., H. W. Barkema, J. De Buck, S. De Vliegher, M. Chaffer, J. Lewis, and G. P. Keefe. 2017. Identification of bovine-associated 
coagulase-negative staphylococci by matrix-assisted laser desorption/ionization time-of-flight mass spectrometry using a direct transfer protocol. J. Dairy Sci. 100:2137-2147.

Canovas, J., M. Baldry, M. S. Bojer, P. S. Andersen, P. K. Grzeskowiak, M. Stegger, P. Damborg, C. A. Olsen, and H. Ingmer. 2016. Cross-talk between Staphylococcus aureus and other staphylococcal species via the agr quorum sensing system. Front. Microbiol. $7: 1733$.

Carretto, E., D. Barbarini, I. Couto, D. De Vitis, P. Marone, J. Verhoef, H. DeLencastre, and S. Brisse. 2005. Identification of coagulase-negative staphylococci other than Staphylococcus epidermidis by automated ribotyping. Clin. Microbiol. Infect. 11:177-184.

Chan, P. F., and S. J. Foster. 1998. The role of environmental factors in the regulation of virulence-determinant expression in Staphylococcus aureus 8325-4. Microbiology 144:2469-2479.

Condas, L. A. Z., J. De Buck, D. B. Nobrega, D. A. Carson, J. P. Roy, G. P. Keefe, T. J. DeVries, J. R. Middleton, S. Dufour, and H. W. Barkema. 2017. Distribution of non-aureus staphylococci species in udder quarters with low and high somatic cell count, and clinical mastitis. J. Dairy Sci. 100:5613-5627.

De Visscher, A., S. Piepers, F. Haesebrouck, and S. De Vliegher. 2016a. Intramammary infection with coagulase-negative staphylococci at parturition: Species-specific prevalence, risk factors, and effect on udder health. J. Dairy Sci. 99:6457-6469.

De Visscher, A., S. Piepers, F. Haesebrouck, and S. De Vliegher. 2016b. Teat apex colonization with coagulase-negative Staphylococcus species before parturition: Distribution and species-specific risk factors. J. Dairy Sci. 99:1427-1439.

De Visscher, A., K. Supré, F. Haesebrouck, R. N. Zadoks, V. Piessens, E. Van Coillie, S. Piepers, and S. De Vliegher. 2014. Further evidence for the existence of environmental and host-associated species of coagulase-negative staphylococci in dairy cattle. Vet. Microbiol. 172:466-474.

De Vliegher, S., H. Laevens, L. A. Devriese, G. Opsomer, J. L. Leroy, H. W. Barkema, and A. W. De Kruiff. 2003. Prepartum teat apex colonization with Staphylococcus chromogenes in dairy heifers is associated with low somatic cell count in early lactation. Vet. Microbiol. 92:245-252.

De Vliegher, S., G. Opsomer, A. Vanrolleghem, L. A. Devriese, O. C. Sampimon, J. Sol, H. W. Barkema, F. Haesebrouck, and A. de Kruif. 2004. In vitro growth inhibition of major mastitis pathogens by Staphylococcus chromogenes originating from teat apices of dairy heifers. Vet. Microbiol. 101:215-221.

Dohmen, W., F. Neijenhuis, and H. Hogeveen. 2010. Relationship between udder health and hygiene on farms with an automatic milking system. J. Dairy Sci. 93:4019-4033.

Dolder, C., B. H. P. van den Borne, J. Traversari, A. Thomann, V Perreten, and M. Bodmer. 2017. Quarter- and cow-level risk factors for intramammary infection with coagulase-negative staphylococci species in Swiss dairy cows. J. Dairy Sci. 100:5653-5663.

dos Santos Nascimento, J., P. C. Fagundes, M. A. de Paiva Brito, K. R. dos Santos, and M. do Carmo de Freire Bastos. 2005. Production of bacteriocins by coagulase-negative staphylococci involved in bovine mastitis. Vet. Microbiol. 106:61-71.

Falentin, H., L. Rault, A. Nicolas, D. S. Bouchard, J. Lassalas, P. Lamberton, J. M. Aubry, P. G. Marnet, Y. Le Loir, and S. Even. 2016. Bovine teat microbiome analysis revealed reduced alpha diversity and significant changes in taxonomic profiles in quarters with a history of mastitis. Front. Microbiol. 7:480.

Fry, P. R., J. R. Middleton, S. Dufour, J. Perry, D. Scholl, and I. Dohoo. 2014. Association of coagulase-negative staphylococci species, mammary quarter somatic cell count, and persistence of intramammary infection in dairy cattle. J. Dairy Sci. 97:4876-4885.

Goetz, C., Y. D. N. Tremblay, D. Lamarche, A. Blondeau, A. M. Gaudreau, J. Labrie, F. Malouin, and M. Jacques. 2017. Coagulase-negative staphylococci species affect biofilm formation of other coagulase-negative and coagulase-positive staphylococci. J. Dairy Sci. 100:6454-6464.

Gomes, F., and M. Henriques. 2016. Control of bovine mastitis: Old and recent therapeutic approaches. Curr. Microbiol. 72:377-382.
Hovinen, M., and S. Pyörälä. 2011. Invited review: Udder health of dairy cows in automatic milking. J. Dairy Sci. 94:547-562.

Le, K. Y., and M. Otto. 2015. Quorum-sensing regulation in staphylococci-An overview. Front. Microbiol. 6:1174.

Lilenbaum, W., A. L. Esteves, and G. N. Souza. 1999. Prevalence and antimicrobial susceptibility of staphylococci isolated from saliva of clinically normal cats. Lett. Appl. Microbiol. 28:448-452.

Matthews, K. R., R. J. Harmon, and B. A. Smith. 1990. Protective effect of Staphylococcus chromogenes infection against Staphylococcus aureus infection in the lactating bovine mammary gland. J. Dairy Sci. 73:3457-3462.

National Mastitis Council. 1999. Laboratory Handbook on Bovine Mastitis. National Mastitis Council, Madison, WI.

National Mastitis Council. 2004. Microbiological Procedures for the Diagnosis of Bovine Udder Infections and Determination of Milk Quality, 4th ed. National Mastitis Council, Madison, WI.

Nielsen, A., K. F. Nielsen, D. Frees, T. O. Larsen, and H. Ingmer. 2010. Method for screening compounds that influence virulence gene expression in Staphylococcus aureus. Antimicrob. Agents Chemother. 54:509-512.

Novick, R. P. 1967. In vivo transmission of drug resistance factors between strains of Staphylococcus aureus. J. Exp. Med. 125:45-59.

Otto, M., H. Echner, W. Voelter, and F. Gotz. 2001. Pheromone crossinhibition between Staphylococcus aureus and Staphylococcus epidermidis. Infect. Immun. 69:1957-1960.

Paduch, J. H., E. Mohr, and V. Kromker. 2013. The association between bedding material and the bacterial counts of Staphylococcus aureus, Streptococcus uberis and coliform bacteria on teat skin and in teat canals in lactating dairy cattle. J. Dairy Res. 80:159-164.

Paharik, A. E., C. P. Parlet, N. Chung, D. A. Todd, E. I. Rodriguez, M. J. Van Dyke, N. B. Cech, and A. R. Horswill. 2017. Coagulasenegative staphylococcal strain prevents Staphylococcus aureus colonization and skin infection by blocking quorum sensing. Cell Host Microbe 22:746-756.

Painter, K. L., A. Krishna, S. Wigneshweraraj, and A. M. Edwards. 2014. What role does the quorum-sensing accessory gene regulator system play during Staphylococcus aureus bacteremia? Trends Microbiol. 22:676-685.

Parker, K. I., C. Compton, F. M. Anniss, A. Weir, C. Heuer, and S. McDougall. 2007. Subclinical and clinical mastitis in heifers following the use of a teat sealant precalving. J. Dairy Sci. 90:207-218.

Pengov, A. 2001. The role of coagulase-negative Staphylococcus spp. and associated somatic cell counts in the ovine mammary gland. J. Dairy Sci. 84:572-574.

Penna, B., R. Varges, L. Medeiros, G. M. Martins, R. R. Martins, and W. Lilenbaum. 2010. Species distribution and antimicrobial susceptibility of staphylococci isolated from canine otitis externa. Vet. Dermatol. 21:292-296.

Piepers, S., K. Peeters, G. Opsomer, H. W. Barkema, K. Frankena, and S. De Vliegher. 2011. Pathogen group specific risk factors at herd, heifer and quarter levels for intramammary infections in early lactating dairy heifers. Prev. Vet. Med. 99:91-101.

Piessens, V., E. Van Coillie, B. Verbist, K. Supré, G. Braem, A. Van Nuffel, L. De Vuyst, M. Heyndrickx, and S. De Vliegher. 2011. Distribution of coagulase-negative Staphylococcus species from milk and environment of dairy cows differs between herds. J. Dairy Sci. 94:2933-2944.

Quirk, T., L. K. Fox, D. D. Hancock, J. Capper, J. Wenz, and J. Park. 2012. Intramammary infections and teat canal colonization with coagulase-negative staphylococci after postmilking teat disinfection: Species-specific responses. J. Dairy Sci. 95:1906-1912.

Rasmussen, M. D. 2006. Automatic milking and udder health: An overview. World Buiatrics Congress 2006 - Nice, France. Accessed Jul. 19, 2017. http://citeseerx.ist.psu.edu/viewdoc/download?doi $=10 \cdot 1 \cdot 1.563 .9122 \& \mathrm{rep}=$ rep1\&type $=$ pdf

Reyher, K. K., I. R. Dohoo, D. T. Scholl, and G. P. Keefe. 2012. Evaluation of minor pathogen intramammary infection, susceptibility parameters, and somatic cell counts on the development of new intramammary infections with major mastitis pathogens. J. Dairy Sci. 95:3766-3780. 
Sawant, A. A., B. E. Gillespie, and S. P. Oliver. 2009. Antimicrobial susceptibility of coagulase-negative Staphylococcus species isolated from bovine milk. Vet. Microbiol. 134:73-81.

Singh, R., and P. Ray. 2014. Quorum sensing-mediated regulation of staphylococcal virulence and antibiotic resistance. Future Microbiol. 9:669-681.

Souza, F. N., S. Piepers, A. M. M. P. Della Libera, M. B. Heinemann, M. M. Cerqueira, and S. De Vliegher. 2016. Interaction between bovine-associated coagulase-negative staphylococci species and strains and bovine mammary epithelial cells reflects differences in ecology and epidemiological behavior. J. Dairy Sci. 99:2867-2874.

Supré, K., F. Haesebrouck, R. N. Zadoks, M. Vaneechoutte, S. Piepers, and S. De Vliegher. 2011. Some coagulase-negative Staphylococcus species affect udder health more than others. J. Dairy Sci. 94:2329-2340.

Taponen, S., J. Björkroth, and S. Pyörälä. 2008. Coagulase-negative staphylococci isolated from bovine extramammary sites and intramammary infections in a single dairy herd. J. Dairy Res. 75:422429 .
Thorberg, B. M., M. L. Danielsson-Tham, U. Emanuelson, and K. Persson Waller. 2009. Bovine subclinical mastitis caused by different types of coagulase-negative staphylococci. J. Dairy Sci. 92:4962-4970.

Vanderhaeghen, W., S. Piepers, F. Leroy, E. Van Coillie, F. Haesebrouck, and S. De Vliegher. 2014. Invited review: Effect, persistence, and virulence of coagulase-negative Staphylococcus species associated with ruminant udder health. J. Dairy Sci. 97:5275-5293.

Vanderhaeghen, W., S. Piepers, F. Leroy, E. Van Coillie, F. Haesebrouck, and S. De Vliegher. 2015. Identification, typing, ecology and epidemiology of coagulase negative staphylococci associated with ruminants. Vet. J. 203:44-51.

Zadoks, R. N., H. G. Allore, H. W. Barkema, O. C. Sampimon, G. J. Wellenberg, Y. T. Grohn, and Y. H. Schukken. 2001. Cow- and quarter-level risk factors for Streptococcus uberis and Staphylococcus aureus mastitis. J. Dairy Sci. 84:2649-2663.

Zadoks, R. N., and J. L. Watts. 2009. Species identification of coagulase-negative staphylococci: Genotyping is superior to phenotyping. Vet. Microbiol. 134:20-28. 